Original article

\title{
Do information differentials and confidence in medical institutions influence out-of-pocket expenditure on health care in India?
}

\author{
Deepabali Bhattacharjee, Pratap C. Mohanty " \\ Dept. of Humanities \& Social Sciences, Indian Institute of Technology of Roorkee, Uttarakhand, 247667, India
}

\section{A R T I C L E I N F O}

\section{Keywords:}

Heath expenditure

OOPE on Health care

Information differentials

Confidence in hospitals

\begin{abstract}
A B S T R A C T
Background: This paper identifies the factors responsible for higher out-of-pocket expenditure on healthcare in India with a focus on confidence in medical institutions and information differentials in the health care sector. Design/methodology/ approach: The analysis is based on IHDS-I (2004-05) and IHDS-II (2011-12) database by applying the log-linear regression method to find out the impact of different independent variables on OOPE (dependent variable). An information index is made using the information related variables available in IHDS dataset by applying the Principal Component Analysis method.

Results: Findings identify that the factors like location, education, age and caste of the respondents play a significant role in determining the out-of-pocket expenditure on health care in India. Further, information differentials and confidence in medical institutions among individuals also play an important role.

Conclusion: Findings suggest policy-based interventions specifically on better dissemination of Information through ICT pertaining to health care. This also prompts for appropriate regulation by Government on hospitals so that confidence among patients as well as information dissemination will be improved, along with a decline in out-of-pocket expenditure on health care.
\end{abstract}

\section{Introduction}

Health care expenditure in India has been a matter of serious concern these days and particularly in the current scenario. The whole episode of Coronavirus Pandemic has made us realise the existing low Public Spending on health care in India and thereby the consequences. With low level of public health spending, Out-of-Pocket Expenditure (OOPE) on health care increases. Health expenditures of the individual or household can be categorized into direct expenditures (Out of Pocket Expenditure or OOPE) and indirect expenditures (prepayments like health insurance or premiums). OOPE is the direct burden of medical costs that households bear at the time of availing healthcare services. Government spending on health care is very low in India. According to Health and Family Welfare Statistics in India, 2019-20, Government Health Expenditure is 1.2\% of GDP, whereas Out of Pocket Expenditure (OOPE) on health is Rs. 340196 crores (58.7\% of THE, $2.2 \%$ of GDP, Rs 2570 per capita). ${ }^{1}$ Thus, household earnings and savings are significant sources of payment for illness.

Literature suggests some of the important factors like age, ${ }^{2,3}$ education, ${ }^{3}$ locations, ${ }^{4}$ income, ${ }^{5}$ confidence or trust in hospitals or doctors, ${ }^{6}$ etc., are responsible for higher Out-of-Pocket Expenditure (OOPE) on health care in India. Although a number of health schemes and facilities are presently operational in India by the government but those facilities are not being effectively accessed by the marginalized section of the society specifically due to lack of awareness and information ${ }^{1}$. Also, the same condition prevails in the EAG (Empowered Action Group) states. These states are vulnerable and socio-economically backward states in India and lag behind in access to basic health facilities. Addressing and involving EAG states will actually bridge the gap in the existing literature. At the same time, along with lack of information, a basic level of confidence or trust is required for any human interaction, with no exception to health care. Confidence in health care is defined as the expectation of a patient from the doctor or the entire health system. ${ }^{7}$ But these factors are not given much attention for higher OOPE on health care in India. Along with other factors, lack of confidence in Government hospitals and low access to information are important factors to be taken care of in connection with high OOPE. Therefore, this paper identifies the various factors responsible for higher

\footnotetext{
* Corresponding author.

E-mail addresses: deepabalibhattacharjee@gmail.com (D. Bhattacharjee), pratap.mohanty@hs.iitr.ac.in (P.C. Mohanty)

1 Information requires exposure to mass media. It includes uses of telephone or mobile phones, internet subscriptions and broadcasting sector (television and radio services) etc.
} 
OOPE on health care by emphasizing the role of confidence in medical institutions and access to information.

\section{Literature review}

Existing health system in India is mainly dependent on OOPE on health care, unlike many countries in the world. ${ }^{8}$ Earnings of the household and their savings are the major sources of payment for illness in India. ${ }^{5}$ But the under-privileged and marginalized section of the society, particularly the low and middle-income categories, do not have adequate earnings nor savings. Often, their burden of health expenditure exceeds income by a proportion, defined as catastrophic expenditure. This catastrophic healthcare expenditure ${ }^{2}$ compels them to borrow money from other sources. They are eventually trapped into debt and abject poverty. This is nearly seven per cent of the population who are pushed below the poverty line in India because of a high burden of OOPE on health care. ${ }^{9-12}$ OOP medical expenditure is regressive in nature. It imposes inequity and thereby owing to a greater burden on poor families with bigger family sizes and lower annual per capita income than better-off families. Poor people generally have worse health conditions than non-poor as they lack access to resources, particularly monetary resources and low self-health awareness levels. ${ }^{5}$

OOPE on health care varies across regions, states, and also across households. The patients' location signifies their standard of living, and it has linkage on medical expenses. ${ }^{4}$ In fact, the older population, particularly those living in rural areas, had a higher OOPE on health care than urban areas. ${ }^{3}$ Similarly, in urban areas, private and higher quality health services are more easily accessible compare to rural areas. ${ }^{13}$

Age and OOPE on health care are directly correlated. ${ }^{2}$ The out-of-pocket payment for older people is higher compared to the younger population, particularly for the period 1995-96 and 2014. ${ }^{3}$ Moreover, the older people have higher OOPE on health care as compared to the other age groups. ${ }^{14-17}$

Education plays an essential role in determining the variation in OOPE. Literacy level is found to be correlated with the burden of OOP payment on healthcare. ${ }^{3}$ Education improves the analytical abilities of an individual. But the poor people cannot afford good education and thus have less knowledge about medical facilities and their availability.

Despite many efforts since decades regarding the provision of free public health care services, studies regarding national health expenditure in India consistently reveal high levels of OOPE on health care. ${ }^{18}$ The ambulatory illness care majorly require private providers on an average across the states, and this results in over 56\% of total OOPE on health care owing to private providers. ${ }^{19}$ Access to private hospitals has been increased along with an increase in the cost of medical care and the unavailability of necessary medical insurance. In India, these are the most important reasons for poverty and inequality, including direct debt. ${ }^{20}$ In comparison to the public hospitals, the OOPE in private hospitals was more by seven percentage points in 1995-96 to $18.0 \%$ points in 2014 in India. ${ }^{3,21}$ Studies show that the poor quality and inaccessibility of the public health system coupled with an increase in the dominance of the private health sector have resulted in the poor resorting to private care, even though they are interested in seeking care from the public sector. ${ }^{22}$ Also, almost $63 \%$ of clinicians practising in rural India do not have proper medical training. ${ }^{23,24}$ This Information regarding lack of qualified health professionals usually remains unreported for the public domain, creating information differentials among the public. Also, there is inherent nature of informational inequality among physicians and patients. Arrow has identified "informational

\footnotetext{
${ }^{2}$ Catastrophic health expenditure is defined as out-of-pocket spending for health care that exceeds a certain proportion of a household's income with the consequence that households suffer the burden of disease (Bulletin of the World Health Organization 2012; 90:664-671. https://doi.org/10.2471/BLT.12.10 2178).
}

inequality" between patients and physicians and the imperfect information provided by physicians which result in market failure, specifically "a failure to reach optimal in the sense of pareto". ${ }^{25}$ Information is a commodity that has both a cost of production and transmission. Thus, it is not equally distributed to all sections of society. ${ }^{26}$ There is a common understanding that doctors have more relevant information than that of the patients. The personal motivation of the doctor may end up ordering extra tests and prescribing expensive drugs in order to earn more money, to increase income, to receive more favour from pharmaceutical companies, and also using reciprocal referrals to specialists in other fields. ${ }^{27}$ There are also trust issues prevailing in a doctor-patient relationship which shows a lack of transparency in the system. Arrow (1963) discusses the importance of trust in the doctor-patient relationship. The trust factor also arises because the patient wants the doctors to keep their personal medical information secure and undisclosed to anyone else. ${ }^{28}$ Doctors, both in the government and private health care sector, prescribes costly medicines and laboratory tests for their own financial commissions. They even sometimes go to the extent of prescribing unnecessary medicines. Therefore, corruption is prevalent in the health care industry. ${ }^{29}$

By health care Institutions, we mean both government and private medical institutions. Trust and confidence are considered very important in a doctor-patient relationship. The doctors and other health professionals were the most authoritative and used sources of healthcare information. But this relationship has been deteriorating since corruption is prevailing in the health care industry. ${ }^{27,29}$

\section{Data and methodology}

Data is extracted from India Human Development Survey (IHDS I and IHDS II) available in public domain in the IHDS website. This is a nationally representative survey of households jointly organised by the National Council of Applied Economic Research (NCAER), Delhi and the University of Maryland. IHDS I surveyed 41554 households in 1503 villages and 971 urban neighbourhoods across India. In IHDS II, 42152 households were interviewed. The survey has gone through a detailed analysis, including the information related variables and confidence variable which are rare among the databases available in India. Crosstabulation of each independent variable with the dependent variable is made taking into account IHDS II, whereas in regression analysis, we have incorporated both IHDS I and IHDS II. OOPE on health care is divided into quintiles for cross-tabulation analysis. The categories are: very low, low, moderate, high and very high. Two regression models have been specified, given the nature of the data. The log-linear regression method is applied in model 1 and model 2 using the IHDS I and II data, respectively. These are derived using STATA software. PCA technique is applied to derive the information index based on five important indicators (refer to Table 1). PCA method is a mathematical procedure that transforms a number of (possibly) correlated variables into a (smaller) number of uncorrelated variables called principal components. Here, PCA method is employed in order to make an information index for better analysis of the result. The dependent and independent variables are explained in Table 1.

\section{Results}

\subsection{OOPE differentials and socio-economic classification}

Cross-tabulation between age and OOPE on health care is observed (refer to Table 2). As age increases, OOPE on health care also increases significantly. But in the age group ( $>60$ ), this is less as compared to the other two categories. Location is found to have an impact on health care. Table 2 indicates that residents of the less developed village have very high OOPE (36\%) in comparison to the metro urban (6.93\%) population. This is because people of less developed areas face more problems in accessing health facilities. They also have high travel expenses and need 
Table 1

Data and variables Description.

\begin{tabular}{|c|c|c|c|}
\hline Variables & Description & Variable Type & $\begin{array}{l}\text { Expected } \\
\text { Sign }\end{array}$ \\
\hline $\begin{array}{l}\text { Dependent } \\
\text { variable } \\
\text { (model } 1 \text { and } \\
\text { model 2) }\end{array}$ & $\begin{array}{l}\text { Out of Pocket expenditure in } \\
\text { health care (2004-05, 2011- } \\
\text { 12). The variable Ln OOPE is } \\
\text { in log form and it is } \\
\text { calculated by adding the } \\
\text { variables medical out-patient } \\
\text { (total value) and medical in- } \\
\text { patient (total value) minus } \\
\text { the insurance expenditure. }\end{array}$ & $\begin{array}{l}\text { Ratio scale/ } \\
\text { continuous }\end{array}$ & \\
\hline \multicolumn{4}{|c|}{ Independent variables } \\
\hline Age group & $\begin{array}{l}\text { It is divided into three } \\
\text { categories according to the } \\
\text { census report. The categories } \\
\text { defined as }(0-14) \text { years, } \\
\text { (15-59) years and ( } 60 \text { and } \\
\text { above) years. The first } \\
\text { category ( } 0-14) \text { years is } \\
\text { taken as reference category. } \\
\text { The second category is taken } \\
\text { as } 1 \text { and third category as } 2 \text {. }\end{array}$ & ordinal & $(-)$ \\
\hline Location & $\begin{array}{l}\text { Location is divided into } 4 \\
\text { categories. Metro urban ( } 0 \text { ), } \\
\text { other urban (1), more } \\
\text { developed village (2) and less } \\
\text { developed village ( } 3 \text { ). } \\
\text { Metro urban is the reference } \\
\text { category. }\end{array}$ & categorical & $(-/+)$ \\
\hline $\begin{array}{l}\text { Household } \\
\text { expenditure } \\
\text { per capita }\end{array}$ & $\begin{array}{l}\text { This variable is divided into } 5 \\
\text { quantiles. The first quantile } \\
\text { (0) is taken as reference } \\
\text { category. The second } \\
\text { quantile (1), the third } \\
\text { quantile (2), the fourth } \\
\text { quantile (3) and the fifth } \\
\text { quantile (4). }\end{array}$ & ordinal & $(+)$ \\
\hline Education & $\begin{array}{l}\text { This variable is divided into } \\
\text { four categories. Primary (0) } \\
\text { (up to class 5), Secondary (up } \\
\text { to class } 10 \text { ), Higher } \\
\text { secondary, Graduate and } \\
\text { more. } \\
\text { Primary education is the } \\
\text { reference category here. }\end{array}$ & ordinal & $(-)$ \\
\hline Caste & $\begin{array}{l}\text { The categories are Brahmin/ } \\
\text { General/forward (0), OBC } \\
\text { (1) SC (2), ST (3), Others (4). } \\
\text { Brahmin/General/forward is } \\
\text { taken as reference category. }\end{array}$ & nominal & $(+/-)$ \\
\hline Gender Dummy & $\begin{array}{l}\text { Male (1) and Female (2). } \\
\text { Male is the reference } \\
\text { category. }\end{array}$ & Dummy & $(+/-)$ \\
\hline $\begin{array}{l}\text { Husband's } \\
\text { education }\end{array}$ & $\begin{array}{l}\text { This variable is divided into } \\
\text { four categories. Primary (0) } \\
\text { (up to class } 5 \text { ), Secondary (up } \\
\text { to class } 10 \text { ), Higher } \\
\text { secondary, Graduate and } \\
\text { more. } \\
\text { Primary is the reference } \\
\text { category here. }\end{array}$ & ordinal & $(+/-)$ \\
\hline $\begin{array}{l}\text { Confidence }^{\mathrm{a}} \text { in } \\
\text { Government } \\
\text { hospitals }\end{array}$ & $\begin{array}{l}\text { The three categories are- } \\
\text { Hardly any confidence }(0) \text {, } \\
\text { only some confidence (1), } \\
\text { Great deal of confidence (2). } \\
\text { The first one is reference } \\
\text { category. }\end{array}$ & categorical & $(+/-)$ \\
\hline $\begin{array}{l}\text { Confidence in } \\
\text { Private } \\
\text { hospitals }\end{array}$ & $\begin{array}{l}\text { The three categories are- } \\
\text { Hardly any confidence }(0) \text {, } \\
\text { only some confidence ( } 1) \text {, } \\
\text { Great deal of confidence (2). } \\
\text { The first one is reference } \\
\text { category. }\end{array}$ & ordinal & $(+/-)$ \\
\hline $\begin{array}{l}\text { Information } \\
\text { Index }\end{array}$ & $\begin{array}{l}\text { It includes five variables: i) } \\
\text { Reading Newspaper- It has } 3\end{array}$ & & $(-)$ \\
\hline
\end{tabular}

Table 1 (continued)

\begin{tabular}{|c|c|c|c|}
\hline Variables & Description & Variable Type & $\begin{array}{l}\text { Expected } \\
\text { Sign }\end{array}$ \\
\hline & $\begin{array}{l}\text { categories: Never, sometimes } \\
\text { and regularly. } \\
\text { ii) Owns mobile -It has two } \\
\text { categories: Yes and No. } \\
\text { iii) Internet- It has } 2 \\
\text { categories: No and Yes } \\
\text { iv) Acquaintance with } \\
\text { doctors among caste/ } \\
\text { community/relatives- It } \\
\text { has } 2 \text { categories: Yes and } \\
\text { No } \\
\text { v) Acquaintance with } \\
\text { doctors outside caste/ } \\
\text { community/relatives- It } \\
\text { has } 2 \text { categories: Yes and } \\
\text { No. } \\
\text { Information Index has } 3 \\
\text { categories- low (0), mid (1) } \\
\text { and high (2). The category } \\
\text { low (0) is the reference } \\
\text { category. }\end{array}$ & $\begin{array}{l}\text { Categorical } \\
\text { (ordinal) based } \\
\text { on PCA }\end{array}$ & \\
\hline EAG Dummy & $\begin{array}{l}\text { All the states are divided into } \\
\text { two parts- EAG and NON- } \\
\text { EAG states. } \\
\text { The category NON-EAG } \\
\text { states is the reference } \\
\text { category. }\end{array}$ & dummy & $(+)$ \\
\hline
\end{tabular}

Source: Authors' calculation using India Human Development Survey.

a Note: The question asked in IHDS related to confidence- Would you say you have confidence in government hospitals ? Options were: A great deal of confidence $=1$, Only some confidence $=2$. Hardly any confidence at all $=3$. The same set of options were for private hospitals also.

much more time to access hospitals than the people residing in urban areas. ${ }^{13}$ Further, if the OOPE of both more developed and less developed villages combined, then it is almost $66 \%$ of the total. This implies that most of the OOPE are from the villages and remote areas and not from developed or metro cities.

Also, males have almost similar OOPE on health care as females. In Table 2, household expenditure per capita is considered as a proxy for income. The data show that irrespective of the household belonging to different income quintiles, the OOPE is almost similar (the range lies between 19 and 20\%). This implies that even people in the lower quartile of household expenditure spend relatively the same as that of the higher-income group in percentage terms. Thus, OOPE on health care is regressive in nature.

Education has a crucial role to play in the higher OOPE. This is in line with the existing literature. it is argued that literacy level is significantly associated with the burden of OOPE on health care. ${ }^{3}$ In Table 2, we find that people with education up to primary level has the highest (i. e.54.08\%) of the total OOPE. As the level of education increases, OOPE decreases to a significant level (i.e.5.69\% of total OOPE). More education empowers people with more information, and they can analyse the situation and spend accordingly. Thus, OOPE on health care decreases with better education ${ }^{3}$. The education of the head of the family/husband is also essential for decision making in the household, particularly in health-related issues.

\subsection{OOPE and confidence in medical institutions}

\section{Confidence in the institutions of direct health care providers}

\footnotetext{
${ }^{3}$ However, the role of education is better realized on the quality of education. There are various other aspects of education like cognitive skills, non-technical education etc. are also important for discussion. We consider education in specified categories instead of each nitty gritty.
} 
Table 2

Socio-economic Classification of OOPE on health care in India (in percent).

\begin{tabular}{|c|c|c|c|c|c|c|c|}
\hline \multirow[t]{2}{*}{ Socio-economic classification } & & \multicolumn{5}{|c|}{ OOPE in Quintile } & \multirow[t]{2}{*}{ Total } \\
\hline & & Very low & Low & moderate & high & Very high & \\
\hline \multirow[t]{3}{*}{ Age group } & Age $(0-14)$ & 25.92 & 29.99 & 29.09 & 28.56 & 26.67 & 28.05 \\
\hline & age (15-59) & 63.76 & 60.42 & 60.47 & 60.52 & 60.97 & 61.23 \\
\hline & age $>60$ & 10.33 & 9.60 & 10.44 & 10.92 & 12.35 & 10.72 \\
\hline \multirow[t]{4}{*}{ Location } & Metro urban & 7.36 & 6.45 & 7.75 & 6.69 & 6.47 & 6.93 \\
\hline & Other Urban & 27.74 & 26.00 & 27.28 & 26.41 & 27.93 & 27.06 \\
\hline & More Developed Village & 31.05 & 30.02 & 27.62 & 29.16 & 32.07 & 30 \\
\hline & Less Developed Village & 33.85 & 37.54 & 37.35 & 37.74 & 33.53 & 36 \\
\hline \multirow[t]{5}{*}{ Caste } & Brahmin/general/forward & 25.26 & 26.48 & 29.75 & 28.53 & 30.11 & 27.99 \\
\hline & $\mathrm{OBC}$ & 39.61 & 38.93 & 39.98 & 42.25 & 44.86 & 41.11 \\
\hline & SC & 20.74 & 23.85 & 21.29 & 20.62 & 19.07 & 21.14 \\
\hline & ST & 13.08 & 9.82 & 7.78 & 7.23 & 4.48 & 8.51 \\
\hline & Others & 1.32 & 0.91 & 1.20 & 1.36 & 1.47 & 1.25 \\
\hline \multirow[t]{2}{*}{ Gender } & Male & 50.11 & 49.83 & 49.86 & 49.75 & 49.93 & 49.9 \\
\hline & Female & 49.89 & 50.17 & 50.14 & 50.25 & 50.07 & 50.1 \\
\hline \multirow[t]{4}{*}{ Household expenditure per capita } & First quantile & 26.46 & 28.19 & 20.75 & 17.47 & 6.61 & 19.98 \\
\hline & Second quantile & 20.09 & 23.48 & 21.81 & 21.57 & 13.03 & 20.02 \\
\hline & Third quantile & 18.4 & 19.22 & 20.79 & 21.13 & 20.55 & 20 \\
\hline & Fourth quantile & 18.08 & 16.36 & 18.76 & 21.08 & 25.86 & 20 \\
\hline \multirow[t]{4}{*}{ Education } & Primary & 51.42 & 56.85 & 55.02 & 54.70 & 52.35 & 54.08 \\
\hline & Secondary & 34.40 & 32.16 & 32.70 & 32.63 & 33.35 & 33.05 \\
\hline & Higher secondary & 7.63 & 6.38 & 6.93 & 7.18 & 7.84 & 7.19 \\
\hline & Graduate and above & 6.55 & 4.62 & 5.35 & 5.50 & 6.46 & 5.69 \\
\hline \multirow[t]{4}{*}{ Husband's education } & Primary & 82.68 & 84.25 & 82.65 & 83.21 & 81.34 & 82.84 \\
\hline & Secondary & 13.38 & 12.61 & 13.74 & 13.38 & 14.52 & 13.52 \\
\hline & Higher secondary & 3.34 & 2.68 & 3.07 & 2.71 & 3.74 & 3.1 \\
\hline & Graduate and above & 0.6 & 0.46 & 0.54 & 0.71 & 0.4 & 0.54 \\
\hline
\end{tabular}

Source: Authors' calculation using India Human Development Survey II.

determines health care expenditure to a significant level. The data in Table 3 reveals that as the intensity of trust and confidence increases, OOPE on health care increases in both government and private hospitals. ${ }^{27}$ Patients often take the doctor's suggestions without questioning them. This may lead to an increase in $\mathrm{OOPE}^{29}$

\subsection{OOPE and information differentials}

Three hundred sixty-eight private FM radio stations were operational by the end of March 2020, besides public service broadcasters. All India Radio (AIR) have a network of 418 stations and 606 broadcast transmitters. As of March 2020, urban telephone subscribers are 656.46 million people, whereas rural telephone subscribers are 521.51 million people. In the case of internet subscription, urban internet subscriber per 100 population is 99.12 whereas rural internet subscriber per 100 population is 32.24 only. ${ }^{30}$ These data show that urban people have more access to information as compared to rural.

The information index is composed of five variables - reading newspaper, own mobile, internet access, acquaintance with doctors

Table 3

Confidence in hospitals or doctors and OOPE on health care differentials.

\begin{tabular}{lllllllll}
\hline \multicolumn{2}{l}{$\begin{array}{l}\text { Confidence in hospitals } \\
\text { and doctors to provide } \\
\text { good treatment }\end{array}$} & \multicolumn{2}{l}{ OOPE in quintile } & \multicolumn{3}{l}{ Total } \\
\cline { 2 - 6 } & $\begin{array}{l}\text { Very } \\
\text { low }\end{array}$ & low & mid & high & $\begin{array}{l}\text { Very } \\
\text { high }\end{array}$ & \\
\hline Govt. & $\begin{array}{l}\text { A great deal } \\
\text { of confidence } \\
\text { Only some } \\
\text { confidence }\end{array}$ & 56.68 & 51.64 & 54.05 & 55.18 & 51.1 & 53.72 \\
& $\begin{array}{l}\text { Hardly any } \\
\text { confidence } \\
\text { Great deal of } \\
\text { Private }\end{array}$ & 73.19 & 74.17 & 11.00 & 10.99 & 10.55 & 12.72 & 11.08 \\
& $\begin{array}{l}\text { confidence } \\
\text { Only some } \\
\text { confidence }\end{array}$ & 22.62 & 22.73 & 23.54 & 22.9 & 21.91 & 22.73 \\
$\begin{array}{l}\text { Hardly any } \\
\text { confidence }\end{array}$ & 4.19 & 3.14 & 3.96 & 5.39 & 4.59 & 4.25 \\
\hline
\end{tabular}

Source: Authors' calculation using India Human Development Survey II. among caste/community/relatives and acquaintance with doctors outside caste/community/relatives, using Principal Component Analysis (PCA) method. In this index, the OOPE on health care is relatively high when information is low. As the level of information increases, OOPE decreases. Access to information and the impact on OOPE is discussed in detail in Fig. 1.

We observe that those who never read newspapers have the highest OOPE in comparison to those who read newspapers frequently (sometimes or regularly). Newspaper is one of the major sources of information. So, reading newspapers regularly gives access to information which helps in the reduction of OOPE on health care.

Further, mobile phones, internet facilities and acquaintance with doctors (both among and outside the community) also serves as the major sources of information. The data reveals that those who own mobile phones have significantly less OOPE as compared to those who do not have. A similar case is also observed in the access to internet facilities.

Considering acquaintances with doctors (both among and outside

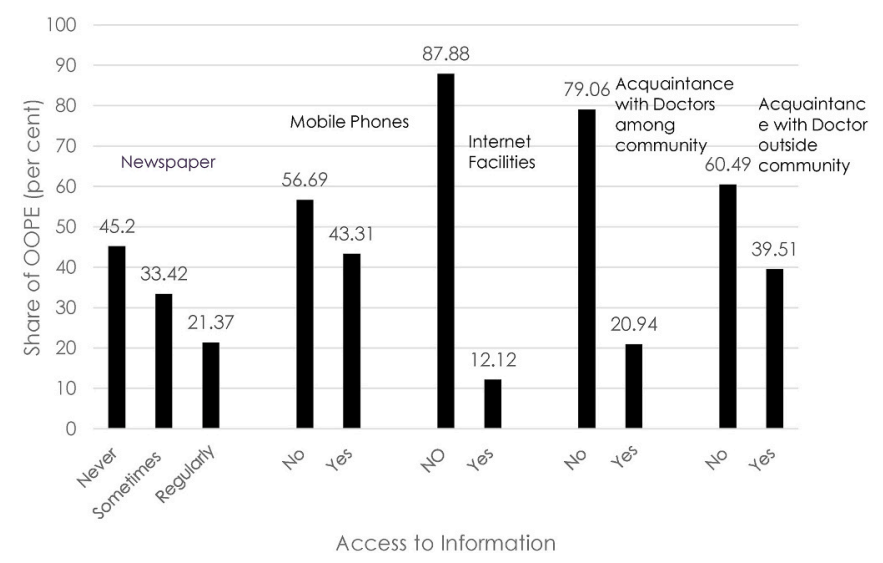

Fig. 1. Access to information and OOPE Source: Authors' estimation from India human development survey II. 
the community), we see that those who have acquaintances with doctors (both among the community and outside the community) have significantly less OOPE on health care compared to those who do not have much known people or doctors in that particular area.

\section{Model specification}

The following regression models are specified to draw the inferences given the data (please refer to variable description Table 1 as well as descriptive statistics Table 4).

We use log-linear regression model based on the dependent and independent variables as described in Table 1.

Model 1 (Log-Linear OLS using IHDS I)

Ln OOPE I(2004-05) $=\beta_{0}+\beta_{1}$ HHEXP $+\beta_{2}$ LOCATION $+\beta_{3}$ AGE $+\beta_{4}$ EDUCATION $+\beta_{5}$ CASTE $+\beta_{6}$ GENDER $+\beta_{7}$ HUSEDU $+\beta_{8}$ CONF $+\beta_{9}$ INFO_INDEX $+\beta_{10}$ EAGvsNON-EAG $+\varepsilon$ i

Model 2 (Log-Linear OLS using IHDS II)

Ln OOPE EDUCATION $+\mathrm{A}_{5}$ CASTE $+\mathrm{A}_{6}$ GENDER $+\mathrm{A}_{7}$ HUSEDU $+\mathrm{A}_{8} \mathrm{CONF}+$ $\mathrm{A}_{9}$ INFO_INDEX $+\mathrm{A}_{10}$ EAGvsNON-EAG $+\varepsilon j$

These results are derived using a log-linear regression model by using both rounds of IHDS. The dependent variable (OOPE) is in logarithmic form and has been normalised. The mean vif (Variance Inflation Factor) value is $1.16(<10)$, i.e. there is no presence of multicollinearity.

Table 4

Descriptive Statistics of two regression models.

\begin{tabular}{|c|c|c|c|c|}
\hline & \multicolumn{2}{|c|}{ Model 1} & \multicolumn{2}{|c|}{ Model 2} \\
\hline & Mean & S.D. & Mean & S.D. \\
\hline \multicolumn{5}{|l|}{ Age $(0-14 \circledast)$} \\
\hline (15-59) years & 0.588 & 0.492 & 0.818 & 0.386 \\
\hline$>60$ years & 0.084 & 0.277 & 0.055 & 0.228 \\
\hline \multicolumn{5}{|l|}{ Gender $($ Male ()} \\
\hline Female & 0.492 & 0.499 & 0.392 & 0.488 \\
\hline \multicolumn{5}{|l|}{ Location (Rural $\circledast$ ) } \\
\hline Urban & 0.306 & 0.461 & 0.413 & 0.492 \\
\hline \multicolumn{5}{|l|}{ Caste (Brahmin ${ }^{\circledR}$ ) } \\
\hline OBC & 0.407 & 0.491 & 0.379 & 0.485 \\
\hline SC & 0210 & 0.407 & 0.340 & 0.474 \\
\hline ST & 0.069 & 0.253 & 0.221 & 0.415 \\
\hline Others & 0.256 & 0.436 & 0.053 & 0.223 \\
\hline \multicolumn{5}{|c|}{ Household exp per capita (very low exp ${ }^{\circledR}$ ) } \\
\hline Low exp & 0.199 & 0.399 & 0.182 & 0.386 \\
\hline Medium exp & 0.201 & 0.401 & 0.202 & 0.402 \\
\hline High exp & 0.203 & 0.403 & 0.215 & 0.411 \\
\hline Very high exp & 0.211 & 0.408 & 0.269 & 0.443 \\
\hline \multicolumn{5}{|l|}{ Education (Primary ${ }^{\circledR}$ ) } \\
\hline Secondary & 0.348 & 0.476 & 0.461 & 0.498 \\
\hline Higher Secondary & 0.056 & 0.231 & 0.127 & 0.333 \\
\hline Graduate & 0.051 & 0.220 & 0.114 & 0.318 \\
\hline \multicolumn{5}{|c|}{ Household head/Husband's education (Primary $\left.{ }^{\circledR}\right)$} \\
\hline Secondary & 0.213 & 0.409 & 0.165 & 0.371 \\
\hline Higher Secondary & 0.015 & 0.123 & 0.047 & 0.211 \\
\hline Graduate & 0.016 & 0.126 & 0.009 & 0.092 \\
\hline \multicolumn{5}{|c|}{ Information Index (low level of info $($ ) } \\
\hline Medium level of info & 0.310 & 0.463 & 0.328 & 0.469 \\
\hline High level of info & 0.324 & 0.468 & 0.336 & 0.472 \\
\hline \multicolumn{5}{|l|}{ EAGvsNONEAG (NonEAG®) } \\
\hline EAG & 0.428 & 0.495 & 0.513 & 0.499 \\
\hline \multicolumn{5}{|c|}{ Confidence in Government hospitals (Hardly any confidence ${ }^{\circledR}$ ) } \\
\hline Only some confidence & 0.279 & 0.449 & 0.354 & 0.478 \\
\hline Great deal of confidence & 0.629 & 0.482 & 0.528 & 0.499 \\
\hline \multicolumn{5}{|c|}{ Confidence in Private hospitals (Hardly any confidence ${ }^{\circledR}$ ) \# } \\
\hline Only some confidence & - & - & 0.195 & 0.396 \\
\hline Great deal of confidence & - & - & 0.770 & 0.420 \\
\hline
\end{tabular}

Source: Authors' estimation using IHDS I and IHDS II.

Note: \# This variable was not covered in IHDS I.

$\sim$ These variables are not considered as control variables in model 3.

\subsection{Regression results and analysis}

The regression models in this paper are well specified by including relevant variables. The interpretation of the slope coefficient of age (third group, i.e. above 60 years) is 0.073 for model 1 indicates that if the age of the respondent increases by one year, then OOPE increases by $7.3 \%$, given the reference category (age group $0-14$ years). It is significant at one per cent level. IHDS II also gives a similar result (Table 5). Location is another important control variable since it is significant in both the models and justify the existing literature. ${ }^{4}$ If the resident belongs to urban areas, then OOPE on health care decreases as compared to those residing in rural areas. This is because, in urban areas, private as well as but higher quality health services (do not have to go time and again) are more easily accessible compared to the rural areas. ${ }^{13}$

Education is found to be an important variable significant at one per cent level. The regression result in Table 5 finds a negative relationship between the level of education and OOPE on health care. ${ }^{3}$ It is observed in both models. Household expenditure per capita has a positive relationship with OOPE and is statistically significant at one per cent level. Household expenditure per capita is a proxy variable for income. As income increases, people are generally ready to spend more on quality healthcare, thereby expected to incur higher expenditure. Earnings and savings are the main sources of payment for illness. ${ }^{5}$ The marginalized section of the society who are struggling every single day for their hand to mouth, cannot give much attention to their health issues. A hungry man cannot prioritize anything except food. When income increases, people are inclined towards better health facilities and hence OOPE increases. This is justified in both models (Table 5).

The variable 'confidence in Government hospitals' matters in variation of OOPE. The slope coefficient shows that as people are more confident in Government medical institutions, OOPE on health care decreases. Also, there is a long waiting time in government hospitals which either increases the transportation cost or patients prefer to visit government doctors practising in private hospitals. OOPE is positively linked to confidence in private hospitals (Table 5).

Information level as proxied by the 'information index' is negatively linked to OOPE in IHDS I and significant for high level of information. In the case of IHDS II, it is significant for both medium and high level of information but with a positive sign. The positive sign of the coefficient may be because of the fact that as we have more information, we have more knowledge about the health facilities available and know more about the consequences of various diseases (Table 5). Thus, OOPE might increase significantly.

The slope coefficient of EAG ${ }^{4}$ (Empowered Action Group) vs NONEAG is insignificant in IHDS I but highly significant in model 2, showing that OOPE increases in the case of EAG states as compared to non-EAG states. This justifies the fact that EAG states are much more vulnerable as compared to the Non-EAG states and have high OOPE on health care.

\section{Conclusion}

OOPE on health care is among the serious concerns in India despite many steps undertaken by the Government. The findings in this paper show that age, location, education, caste, household head/husband's education, confidence in government/private hospitals are the significant determinants of OOPE on health care in India. Our regression results indicate that age and health expenditure is positively related, which is found similar with the existing literature. ${ }^{3,14}$ Similarly,

\footnotetext{
${ }^{4}$ Empowered Action Group (EAG) states are composed of nine high focussed states with relatively high fertility and mortality. These states are considered vulnerable by the Government and require special attention. EAG states include Uttarakhand, Rajasthan, Uttar Pradesh, Bihar, Jharkhand, Odisha, Chhattisgarh, Madhya Pradesh and Assam.
} 
Table 5

Results of log linear OLS regression models.

\begin{tabular}{|c|c|c|}
\hline & Model 1 & Model 2 \\
\hline Log (OOPE) & Coef. & Coef. \\
\hline \multicolumn{3}{|l|}{ Age $(0-14 ®)$} \\
\hline (15-59) years & $\begin{array}{l}-0.017 \\
(0.011)\end{array}$ & $\begin{array}{l}0.057 \\
(0.043)\end{array}$ \\
\hline$>60$ years & $\begin{array}{l}0.073^{* * *} \\
(0.018)\end{array}$ & $\begin{array}{l}0.188^{* * *} \\
(0.071)\end{array}$ \\
\hline \multicolumn{3}{|l|}{ Gender (Male $\Re)$} \\
\hline Female & $\begin{array}{l}0.007 \\
(0.009)\end{array}$ & $\begin{array}{l}0.019 \\
(0.028)\end{array}$ \\
\hline \multicolumn{3}{|l|}{ 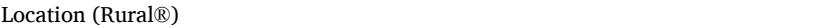 } \\
\hline Urban & $\begin{array}{l}-0.283^{* * *} \\
(0.011)\end{array}$ & $\begin{array}{l}-0.445^{* * *} \\
(0.030)\end{array}$ \\
\hline \multicolumn{3}{|l|}{ Caste $($ Brahmin $®)$} \\
\hline OBC & $\begin{array}{l}0.352^{* * *} \\
(0.021)\end{array}$ & $\begin{array}{l}-0.775^{* * *} \\
(0.182)\end{array}$ \\
\hline SC & $\begin{array}{l}0.273^{* * *} \\
(0.023)\end{array}$ & $\begin{array}{l}-0.777^{* *} \\
(0.182)\end{array}$ \\
\hline ST & $\begin{array}{l}0.047^{*} \\
(0.027)\end{array}$ & $\begin{array}{l}-0.789^{* * *} \\
(0.182)\end{array}$ \\
\hline Others & $\begin{array}{l}0.169 * * * \\
(0.022)\end{array}$ & $\begin{array}{l}-1.939 * * * \\
(0.190)\end{array}$ \\
\hline \multicolumn{3}{|c|}{ Household exp per capita (very low exp ${ }^{\circledR}$ ) } \\
\hline Low exp & $\begin{array}{l}0.691 * * * \\
(0.015)\end{array}$ & $\begin{array}{l}0.569 * * * \\
(0.049)\end{array}$ \\
\hline Medium exp & $\begin{array}{l}1.119 * * * \\
(0.016)\end{array}$ & $\begin{array}{l}0.992 * * * \\
(0.049)\end{array}$ \\
\hline High exp & $\begin{array}{l}1.527 * * * \\
(0.016)\end{array}$ & $\begin{array}{l}1.215^{* * *} \\
(0.051)\end{array}$ \\
\hline Very high exp & $\begin{array}{l}2.171^{* * *} \\
(0.018)\end{array}$ & $\begin{array}{l}1.846^{* * *} \\
(0.053)\end{array}$ \\
\hline \multicolumn{3}{|l|}{$\begin{array}{l}\text { Education (Primary®) of } \\
\text { respondent }\end{array}$} \\
\hline Secondary & $\begin{array}{l}-0.075^{* * *} \\
(0.011)\end{array}$ & $\begin{array}{l}-0.338^{* * *} \\
(0.034)\end{array}$ \\
\hline Higher Secondary & $\begin{array}{l}-0.122^{* * *} \\
(0.022)\end{array}$ & $\begin{array}{l}-0.442^{* * *} \\
(0.049)\end{array}$ \\
\hline Graduate & $\begin{array}{l}-0.185^{* * *} \\
(0.024)\end{array}$ & $\begin{array}{l}-0.644 * * * \\
(0.054)\end{array}$ \\
\hline \multicolumn{3}{|c|}{ head/Husband's education (Primary ${ }^{\circledR}$ ) } \\
\hline Secondary & $\begin{array}{l}-0.033^{*} \\
(0.012)\end{array}$ & $\begin{array}{l}-0.221^{* * *} \\
(0.039)\end{array}$ \\
\hline Higher Secondary & $\begin{array}{l}-0.118^{* *} \\
(0.038)\end{array}$ & $\begin{array}{l}-0.282^{*} \\
(0.068)\end{array}$ \\
\hline Graduate & $\begin{array}{l}0.009 \\
(0.039)\end{array}$ & $\begin{array}{l}-1.037^{* * *} \\
(0.151)\end{array}$ \\
\hline \multicolumn{3}{|c|}{ Information Index (low level of info $®$ ) } \\
\hline Medium level of info & $\begin{array}{l}-0.009 \\
(0.012)\end{array}$ & $\begin{array}{l}0.192^{* * *} \\
(0.034)\end{array}$ \\
\hline High level of info & $\begin{array}{l}-0.045^{* * *} \\
(0.013)\end{array}$ & $\begin{array}{l}0.200 * * * \\
(0.038)\end{array}$ \\
\hline EAGvsNONEAG (NonEAG () & & \\
\hline EAG & $\begin{array}{l}-0.016 \\
(0.010)\end{array}$ & $\begin{array}{l}0.569 * * * \\
(0.030)\end{array}$ \\
\hline Confidence in Government 1 & ls (Hardly any confiden & \\
\hline Only some confidence & $\begin{array}{l}-0.101^{* * *} \\
(0.018)\end{array}$ & $\begin{array}{l}-0.063 \\
(0.046)\end{array}$ \\
\hline Great deal of confidence & $\begin{array}{l}-0.088^{* * *} \\
(0.016)\end{array}$ & $\begin{array}{l}-0.144^{* * *} \\
(0.044)\end{array}$ \\
\hline Confidence in Private hospit & ardly any confidence $(\mathbb{B})$ & \\
\hline Only some confidence & - & $\begin{array}{l}-0.014 \\
(0.080)\end{array}$ \\
\hline Great deal of confidence & - & $\begin{array}{l}0.055 \\
(0.076)\end{array}$ \\
\hline Constant & $\begin{array}{l}5.312 \\
(0.030)\end{array}$ & $\begin{array}{l}5.783 \\
(0.204)\end{array}$ \\
\hline & $\begin{array}{l}\text { No. of obs }=138136 \\
\mathrm{~F}(23,138112)= \\
952.93\end{array}$ & $\begin{array}{l}\text { No. of obs }=53919 \\
F(25,53893)=94.30\end{array}$ \\
\hline & $\begin{array}{l}\text { R-squared }=0.1370 \\
\text { Adj. R-squared }= \\
0.1368\end{array}$ & $\begin{array}{l}\text { R-squared }=0.0419 \\
\text { Adj. R-squared }= \\
0.0415\end{array}$ \\
\hline
\end{tabular}

Source: Authors' estimation using IHDS-I and IHDS-II.

Note: Standard errors are in parentheses.

* Significant at $10 \%$. ** Significant at $5 \%$ and $* * *$ significant at $1 \%$ level. variables like location and education also justify the existing literature. ${ }^{3,4}$

The paper also identifies the role of information differentials and confidence in medical institutions, which influence OOPE on health care significantly. This is important because patients are very vulnerable to the problems of existing corruption in the health care sector. ${ }^{29}$ This is in concordance with the National Health Policy, 2017 directions towards a significant reduction in OOPE, specifically on strengthening the trust and confidence of the common man in government hospitals. This is going to be a holistic approach by making it predictable, efficient, patient-centric, affordable, effective and inclusive. Better regulation by the Government will improve confidence and trust among patients along with a decline in OOPE on health care. Also, the declining quality and inaccessibility of government hospitals force people to access private hospitals, even though they are interested in government hospitals. ${ }^{22}$ Therefore, the authorities are responsible to strengthen the accessibility and affordability of the healthcare services being provided to the population. ${ }^{31}$ Nonetheless, information differentials have not been paid attention to by the policymakers in India so far to be considered as an important factor. Moreover, our findings suggest that information differentials influence OOPE. Therefore, it is suggested that more specific interventions are required to improve the information differential, like wider use of ICT tools in order to lower the OOPE on healthcare in India.

\section{Limitation of the study}

Since the paper deals with qualitative issues like information differential and confidence in medical institutions, the study is limited to IHDS (India Human Development Survey) database. Such variables are hardly available in other databases.

\section{CRediT authorship contribution statement}

Deepabali Bhattacharjee: Conceptualization, literature review, data filtering, empirical estimation, Formal analysis. Pratap C. Mohanty: Conceptualization, Supervision, reviewing and analysis of the results from the policy perspectives.

\section{Declaration of competing interest}

The authors declare that they have no competing interests.

\section{References}

1 Health and Family Welfare Statistics in India 2019-20, Ministry of Health and Family Welfare, Government of India. Available online: https://main.mohfw.gov.in/newshi ghlights-19.

2 Pascual-Saez M, Cantarero-Prieto D, Castañeda D. Public health expenditure, GDP and the elderly population: a comparative study. Int J Soc Econ. 2017 Oct 9.

3 Pandey A, Clarke L, Dandona L, Ploubidis GB. Inequity in out-of-pocket payments for hospitalisation in India: evidence from the national sample surveys, 1995-2014. Soc Sci Med. 2018 Mar 1;201:136-147.

4 O'Donnell O, van Doorslaer E, Rannan-Eliya RP, et al. Explaining the incidence of catastrophic expenditures on health care: comparative evidence from Asia. EQUITAP. 2005 Jun; 5.

5 Misra S, Awasthi S, Singh JV, Agarwal M, Kumar V. Estimation of out of pocket direct and indirect medical expenditure and spending burden ratio across income quintiles in urban Lucknow, India. Clinical Epidemiol Glob Health. 2013 Apr 1;1(1):12-18.

6 Kulkarni VS, Kulkarni VS, Gaiha R. Trust in Hospitals-Evidence from India.

7 Gopichandran V, Chetlapalli SK. Dimensions and determinants of trust in health care in resource poor settings-a qualitative exploration. PLoS One. 2013 Jul 16;8(7), e69170.

8 Reddy KS, Patel V, Jha P, Paul VK, Kumar AS, Dandona L. Lancet India Group for Universal Healthcare. Towards achievement of universal health care in India by 2020: a call to action. Lancet. 2011 Feb 26;377(9767):760-768.

9 Shahrawat R, Rao KD. Insured yet vulnerable: out-of-pocket payments and India's poor. Health Pol Plann. 2012 May 1;27(3):213-221.

10 Garg CC, Karan AK. Reducing out-of-pocket expenditures to reduce poverty: a disaggregated analysis at rural-urban and state level in India. Health Pol Plann. 2009 Mar 1;24(2):116-128. 
11 Kumar K, Singh A, Kumar S, et al. Correction: socio-economic differentials in impoverishment effects of out-of-pocket health expenditure in China and India: evidence from WHO SAGE. PLoS One. 2015 Sep 14;10(9), e0138499.

12 Van Doorslaer E, O'Donnell O, Rannan-Eliya RP, et al. Effect of payments for health care on poverty estimates in 11 countries in Asia: an analysis of household survey data. The lancet. 2006 Oct 14;368(9544):1357-1364.

13 Basumatary J, Srivastav N. Out-of-Pocket health care expenditure and poverty in Assam. IOSR J Humanit Soc Sci. 2017;22(2):76-82.

14 Kim SG, Park WS, Chung WJ, Yu SH. Out-of-pocket health expenditures by nonelderly and elderly persons in Korea. J Prevent Med Pub Health. 2005;38(4):408-414.

15 Mohanty SK, Chauhan RK, Mazumdar S, Srivastava A. Out-of-pocket expenditure on health care among elderly and non-elderly households in India. Soc Indicat Res. 2014 Feb 1;115(3):1137-1157.

16 Kumara AS, Samaratunge R. Patterns and determinants of out-of-pocket health care expenditure in Sri Lanka: evidence from household surveys. Health Pol Plann. 2016 Oct 1;31(8):970-983.

17 Baird K. High out-of-pocket medical spending among the poor and elderly in nine developed countries. Health Serv Res. 2016 Aug;51(4):1467-1488.

18 Berman PA. National health accounts in developing countries: appropriate methods and recent applications. Health Econ. 1997 Jan;6(1):11-30.

19 Berman PA. Rethinking health care systems: private health care provision in India. World Dev. 1998 Aug 1;26(8):1463-1479.

20 Balarajan Y, Selvaraj S, Subramanian SV. Health care and equity in India. Lancet 2011 Feb 5;377(9764):505-515.
21 Bhat R, Jain N. Analysis of public and private healthcare expenditures. Econ Polit Wkly. 2006 Jan 7:57-68.

22 Gwatkin DR. Health inequalities and the health of the poor: what do we know? What can we do? Bull World Health Organ. 2000;78:3-18.

23 Rao M, Rao KD, Kumar AS, Chatterjee M, Sundararaman T. Human resources for health in India. Lancet. 2011 Feb 12;377(9765):587-598.

24 Rao KD, Bhatnagar A, Berman P. So many, yet few: human resources for health in India. Hum Resour Health. 2012 Dec;10(1):1-9.

25 Arrow KJ. Uncertainty and the welfare economics of medical care. World Health Organization. Bull World Health Organ. 2004 Feb 1;82(2):141.

26 Haas-Wilson D. Arrow and the information market failure in health care: the changing content and sources of health care information. InUncertain Times. 2003 Dec 8:169-180. Duke University Press.

27 Shmanske S. Information asymmetries in health services: the market can cope. Indepen Rev. 1996 Oct 1;1(2):191-200.

28 Small S, Peddie D, Ackerley C, Hohl C, Balka E. Patient experiences with informational discontinuity of care: bridging the gaps. Procedia Comput Sci. 2017 Jan 1;113:295-302.

29 Paul S, Bhatia V. Doctor patient relationship: changing scenario in India. Asian J Med Sci. 2016 Jul 4;7(4):1-5.

30 Telecom regulatory authority of India report, 2019-20. Available from https://www. trai.gov.in/sites/default/files/Annaul_Report_02032021_0.pdf.

31 Sethi N, Mohanty S, Das A, Sahoo M. Health expenditure and economic growth nexus: empirical evidence from south Asian countries. Global Bus Rev. 2020, 0972150920963069. 